\title{
FORMAÇÃO DE EDUCADORES PARA A ALFABETIZAÇÃO DE JOVENS E ADULTOS: CONTRIBUIÇÕES DE UM PROJETO DE EXTENSÃO
}

\section{TRAINING OF EDUCATORS FOR THE LITERACY OF YOUNG PEOPLE AND ADULTS: CONTRIBUTIONS TO AN EXTENSION PROJECT}

\author{
Jaqueline Luzia da Silva ${ }^{75}$
}

\section{Resumo}

O objetivo do presente trabalho é descrever a experiência de um projeto de extensão universitária, além de analisar as principais contribuições desta experiência. O projeto "Desafios e possibilidades atuais na Alfabetização de Jovens e Adultos" é responsável pela criação de um grupo de estudos e pesquisas sobre alfabetização e pelo oferecimento de cursos de extensão para interessados na área, principalmente graduandos do Curso de Pedagogia. Esse trabalho busca contribuir com a formação continuada dos educadores da Educação de Jovens e Adultos (EJA), com a formação inicial dos estudantes envolvidos e fomentar a pesquisa sobre a prática dos professores participantes, refletindo e repensando sua realidade a partir dos estudos realizados nos encontros presenciais.

Palavras-chave: Educação de Jovens e Adultos (EJA), alfabetização, formação de educadores, extensão universitária

\begin{abstract}
The purpose of this paper is to describe the experience of a university extension project, in addition to analyzing the main contributions of this experience. The Project "Current Challenges and Possibilities in Literacy for Young People and Adults" is responsible for creating a group of studies and research on literacy and for offering extension courses for those interested in the area, mainly graduates of the Pedagogy Course. This work seeks to contribute to the continuing education of Youth and Adult Education (EJA) educators, with the initial education of the students involved and to foster research on the practice of participating teachers, reflecting and rethinking their reality based on the studies carried out in the face-to-face meetings.
\end{abstract}

Keywords: Youth and Adult Education (EJA), literacy, educator training, University Extension

\footnotetext{
75 Possui graduação em Ciências Sociais pela Universidade Federal do Rio de Janeiro - UFRJ (2002), com licenciatura em Sociologia, Mestrado em Educação pela Universidade Federal do Rio de Janeiro - UFRJ (2005) e Doutorado em Educação pela Pontifícia Universidade Católica do Rio de Janeiro - PUC-Rio (2010). É Professora Adjunta da Universidade do Estado do Rio de Janeiro (UERJ), onde atua na Graduação do Curso de Pedagogia e coordena o Projeto de Extensão "Desafios e possibilidades atuais na Alfabetização de Jovens e Adultos". E-mail:jackluzia@yahoo.com.br. ORCID: https://orcid.org/0000-0001-7164-9542
} 


\section{RevistAleph}

\section{Introdução}

A formação de professores para o trabalho na Educação de Jovens e Adultos (EJA) se constitui em um campo de reflexão/atuação importante, visto que a modalidade tem enfrentado grandes desafios em todo o país, tais como as dificuldades de legitimação e garantia do direito à educação. As taxas de analfabetismo e baixa escolarização da população ${ }^{76}$, o pouco financiamento e a ausência de políticas públicas voltadas para os sujeitos jovens e adultos pouco escolarizados se refletem também no baixo investimento na formação de professores para esta área.

Acredita-se que uma formação alicerçada na realidade será capaz de dar segurança aos futuros educadores, bem como influenciará a construção e reconstrução de suas identidades (ZANETTI, 2008). Ter contato com a EJA ainda na formação acadêmica é um direito dos futuros educadores, pois estes precisam conhecer a modalidade, suas especificidades, os sujeitos que nela chegam e os principais desafios do campo.

Para isso, é importante que a especificidade da EJA seja contemplada na formação inicial do professor e que as transformações sociais orientem a formação continuada. Assim, é bom que a EJA tenha um espaço na formação generalista dos futuros professores e deve ter garantida a atualização dos profissionais que nela atuam (FERREIRA, 2008). Dessa forma, é possível proporcionar um contato com a área, para além da educação voltada para as crianças.

Como a formação para a EJA, para a maioria dos educadores, ocorre ao mesmo tempo em que se dá a atuação em sala de aula, como formação continuada e não formação inicial, seus saberes profissionais se constituem no próprio contexto de ação (DI PIERRO; VÓVIO; ANDRADE, 2008). Assim, as ações formativas são espaços privilegiados de trocas, aprendizagens, construção de planejamentos etc. Por isso, não podem ter um caráter prescritivo e regulador da prática, mas necessitam fomentar a

\footnotetext{
76 É preciso considerar os índices de analfabetismo da população brasileira acima de 15 anos de idade, cerca de 11,5 milhões, o que corresponde a 7\%. Sem contar os sujeitos que não concluíram a Educação Básica, que são cerca de 78 milhões de pessoas, segundo dados da Pesquisa Nacional por Amostra de Domicílios Contínua (Pnad Contínua) 2017.
} 


\section{RevistAleph}

busca, além das relações didáticas tradicionais, de estudos, pesquisas e outras práticas para o aprimoramento da ação educativa.

A formação em EJA também permite ampliar o olhar para outras práticas, exteriores à escolarização, onde a atuação do pedagogo se amplia de acordo com as necessidades da sociedade, desta maneira opondo-se a concepções de uma EJA infantilizada ou instrumentalizada. É pela convicção de que há mudanças significativas em torno da EJA, mesmo que não tão rápidas quanto se espera, que se justifica uma percepção melhor a respeito desse profissional em formação.

O projeto de extensão universitária "Desafios e possibilidades atuais na Alfabetização de Jovens e Adultos", desde o ano de 2016, trata de questões específicas da alfabetização na modalidade da EJA, com o intuito de possibilitar que os professores e estudantes envolvidos compreendam e problematizem a realidade da EJA, conheçam melhor a modalidade e seus sujeitos e reconheçam a EJA como um direito.

Este projeto de extensão vai ao encontro de uma necessidade dos professores, pesquisadores e estudantes envolvidos, de realizar uma formação para alfabetizadores, que possa contribuir para a ação pedagógica dos educadores. Assim, pretende possibilitar aos futuros pedagogos e licenciados entrarem em contato com a realidade das escolas e dos professores da EJA. As trocas pedagógicas e os debates ocorridos buscaram contribuir para que os estudantes já percebam e se envolvam com as questões práticas do cotidiano das escolas.

A necessidade da formação se reflete na grande procura pelo primeiro curso desse projeto oferecido na Universidade do Estado do Rio de Janeiro (UERJ), que superou as expectativas devido ao grande número de interessados (foram cerca de 600 pessoas interessadas no curso). Este fato chama a atenção por mostrar a demanda para tais cursos na universidade e a necessidade de discussão sobre a área da alfabetização de jovens e adultos.

Nas ações oferecidas pelo projeto, os principais impactos sobre a produção e difusão de novos conhecimentos e metodologias são os estudos promovidos nos encontros, em que os participantes discutem e elaboram questões sobre os desafios presentes na prática alfabetizadora de jovens e adultos. Ao mesmo tempo, os temas 


\section{RevistAleph}

trazidos pelos dinamizadores permitem o diálogo com a prática pedagógica, vislumbrando possibilidades de atuação dos participantes quando estão/estiverem em contato direto com a escola e a sala de aula.

Os encontros tornam-se, assim, momentos em que educadores e futuros professores expõem os principais desafios enfrentados no cotidiano, seus anseios e angústias sobre a aprendizagem de seus educandos. Mas também representam espaços em que são suscitadas reflexões, autoavaliações e construção de saberes.

Não há como traçar na EJA um perfil homogêneo dos sujeitos atendidos, pois há muitos perfis, muitas especificidades, muitas singularidades permeando esse universo. Há diferenças etárias, de gênero, étnicas, de locais de procedência, de religiões, constituições familiares, trajetórias escolares, escolaridade dos pais, de acesso à tecnologia, de inserções e não-inserções no mundo de trabalho etc. Como a EJA é este espaço da diversidade, a prática pedagógica necessita trazer essa diversidade para o debate e a reflexão. Por isso, nos cursos e no grupo de estudos, os participantes discutiram as especificidades dos sujeitos atendidos, suas necessidades de aprendizagem, reconhecendo-os como sujeitos de direitos.

Assim, os participantes das ações do projeto buscaram estudar e investigar como estes sujeitos aprendem, como constroem conhecimentos e como articulam estas aprendizagens com/em seu cotidiano. Além disso, a prática educativa na EJA não pode ser um instrumento de exclusão, mas de formação humana e integral, de garantia do direito à educação. Desta forma, torna-se importante fomentar tal discussão na formação de educadores para esta modalidade de ensino da Educação Básica.

Os objetivos do projeto de extensão buscam compreender e problematizar os principais desafios impostos pela realidade atual para a área da Alfabetização de Jovens e Adultos, aprofundando estudos sobre os processos que contribuem para a reprodução da exclusão educacional de grandes contingentes da população brasileira. Além de procurar produzir novos conhecimentos sobre a Alfabetização de Jovens e Adultos que levem à construção de práticas pedagógicas, dando suporte à formação inicial e continuada dos educadores envolvidos. 


\section{RevistAleph}

\section{Contextualizando o projeto de extensão}

O projeto de extensão realiza-se na Faculdade de Educação da UERJ. Está vinculado ao Sistema de Extensão e submete-se ao Departamento de Extensão, que conduz a abertura de cursos e promoção de eventos no âmbito do projeto, certifica os participantes ao final das etapas e concede bolsas de extensão para o projeto (para estudantes da Pedagogia atuarem no mesmo).

O projeto abriga-se no Curso de Pedagogia da Universidade, mas atende um público diverso, composto não só por estudantes da Pedagogia, mas também por estudantes de outros cursos de graduação da própria UERJ (licenciaturas ${ }^{77}$ ), estudantes de outras Instituições de Ensino Superior, além de professores da EJA e interessados na área.

Na estrutura da Faculdade de Educação, o projeto compõe a área da EJA, representado pela coordenadora, no interior do Departamento de Estudos da Educação Inclusiva e Continuada (DEIC). Outras professoras deste Departamento e de outros Departamentos da Faculdade de Educação também atuam no projeto, além de outros professores que não são docentes da universidade. Em sua maioria, são professoras da área da EJA vinculadas à Rede Municipal de Educação do Rio de Janeiro. Desde o ano de 2016, quando o projeto se iniciou, já houve a participação de 17 professores no total. Estes atuam/atuaram como dinamizadores dos encontros nos cursos de extensão.

Nos dois primeiros anos, o projeto de extensão teve como grande parceira a Gerência de Educação de Jovens e Adultos (GEJA), da Secretaria Municipal de Educação do Rio de Janeiro (SME/RJ). A parceria com a GEJA viabilizou a divulgação e a inscrição dos professores no curso, assim como, auxiliou o diálogo com a coordenação do projeto no sentido do alcance dos objetivos propostos. Neste período, além dos alunos da UERJ, os professores da EJA desta Secretaria também eram atendidos. As escolas às quais estes professores pertenciam foram visitadas e pôde-se ter um contato mais próximo

\footnotetext{
77 Embora a alfabetização seja trabalhada pelos professores dos anos iniciais do Ensino Fundamental e, portanto, pertença ao campo de estudos de estudantes da Pedagogia que trabalharão neste nível de ensino, estudantes de outras licenciaturas também têm procurado os cursos de extensão em alfabetização, demonstrando interesse por essa área.
} 


\section{RevistAleph}

com os participantes. Entretanto, desde o ano de 2018, o projeto já não conta com uma parceria externa à UERJ.

No ano de 2016, foi oferecido o primeiro curso de extensão para alfabetizadores do Programa de Educação de Jovens e Adultos (PEJA), a partir de uma parceria com a GEJA, que objetivou contribuir para o reconhecimento e enfrentamento dos principais desafios da área e para a reflexão sobre a prática dos educadores envolvidos, dando suporte à formação inicial e continuada dos mesmos. O curso se concretizou em uma proposta com duração de 64 horas, com estudo aprofundado de temas como contextualização histórica, política e social da EJA; educação inclusiva na alfabetização; relações étnico-raciais; questões didáticas na alfabetização; adolescentes abrigados e em cumprimento de medidas socioeducativas na EJA; alfabetização e as Tecnologias de Informação e Comunicação; alfabetização e humanidades e a educação artística na alfabetização.

No ano de 2017, foi promovido o segundo curso de extensão, intitulado "Alfabetização de jovens e adultos: enfrentando desafios e apontando possibilidades", de 60 horas, também em parceria com a GEJA. O trabalho foi realizado em encontros mensais com professores orientadores e professores regentes de 15 escolas com PEJA, além de licenciandos do Curso de Pedagogia da UERJ. Nestes dois primeiros cursos, o local de realização dos encontros foi a Secretaria Municipal de Educação.

No primeiro semestre do ano de 2018, já acontecendo na própria Universidade, foi promovido o terceiro curso de extensão, denominado "A atualidade da alfabetização de jovens e adultos: desafios e possibilidades". O curso se concretizou em uma proposta de 30 horas, em encontros quinzenais com professores da EJA, estudantes da UERJ (Pedagogia e demais licenciaturas) e estudantes de outras Instituições de Ensino Superior. Este modelo de curso foi repetido mais duas vezes, no segundo semestre de 2018 e posteriormente em 2019.

Os pesquisadores/formadores da área de EJA que assumiram a tarefa de dinamizar os cursos são ou já foram professores da modalidade, característica que garante aos mesmos um conhecimento profundo sobre a área e suas especificidades. Assim, mais do que aulas, os encontros proporcionaram a troca e o diálogo sobre as 


\section{RevistAleph}

vivências e o cotidiano das escolas de EJA, principalmente levando em consideração que "um dos traços da formação dos educadores de jovens e adultos tem de ser conhecer as especificidades do que é ser jovem, do que é ser adulto" (ARROYO, 2006, p. 22).

\section{Sobre a formação de educadores no âmbito do projeto de extensão}

Toda a formação ocorrida no âmbito do projeto de extensão vai ao encontro do conhecimento e da relação mais próxima com a EJA e, mais particularmente, com a alfabetização destes sujeitos. Para tanto, além dos já listados, são trabalhados conteúdos como: as concepções de alfabetização; a formação de leitores e escritores na EJA; pesquisa, leitura e formação para a EJA; questões atuais na alfabetização de jovens e adultos; as contribuições da sala de leitura para a alfabetização e a avaliação da aprendizagem na EJA.

O Curso de Pedagogia da Faculdade de Educação da UERJ, desde o ano de 1991, oferece formação na área da EJA aos licenciandos. E, mesmo após algumas reformulações curriculares, o curso tem investido tanto na formação por meio das disciplinas oferecidas, quanto em concursos públicos para professores da área.

Ter contato com a área da EJA significa também compreender as principais dificuldades que esta apresenta. Questões como financiamento, legislação, o descompasso entre a formação do professor e a realidade dos alunos em formação, material didático, inserção nos sistemas, necessitam ser trazidas e problematizadas, a fim de que os futuros educadores reconheçam esses desafios. Além disso, processos formativos de educadores devem passar, obrigatoriamente, por desnaturalizar dos processos escolares a reprovação e a evasão presentes na EJA (ZANETTI, 2008). Para tanto, tornam-se necessários estudos aprofundados sobre a constituição política, social e econômica da EJA, bem como os caminhos metodológicos e pedagógicos que se apresentam na realidade escolar.

Assumindo essa compreensão, é relevante trazer a análise feita por Paiva e Fernandes (2016, p. 21) sobre a formação do pedagogo na UERJ, quando foi pensado o desenho curricular do Curso de Pedagogia: 


\section{RevistAleph}

O pedagogo formado precisava compreender, ler criticamente e interferir nessas variadas possibilidades, fundamentado em princípios que sustentavam a área, para produzir, segundo especificidades das instituições que educam e de seus sujeitos, um projeto de intervenção pedagógica adequado aos objetivos de cada ação proposta. Não se formava, apenas, o professor de EJA, mas um pedagogo capaz de formular, gestionar, monitorar e avaliar projetos de educação de jovens e adultos, na dimensão do significado do aprender por toda a vida.

Nesse trecho, percebe-se uma concepção ampliada da formação do pedagogo, que não é só o docente que atua nas escolas, mas o educador que pode tanto trabalhar nas escolas, quanto em outros espaços sociais de formação humana. Por isso, a necessidade de se pensar no papel dessa formação, que vai além da educação formal.

Trabalhar com a EJA requer o reconhecimento de suas duas vertentes: a escolarização e a educação continuada. Desde que foi iniciado, em 1996, e até os dias atuais, o movimento dos Fóruns de EJA do Brasil tem salientado a importância de trazer os educadores para o debate sobre a sua própria formação, discutindo as diretrizes que devem nortear a formação inicial e continuada desse segmento, enquanto profissionais da educação. A luta pela formação de professores ocorre ao mesmo tempo em que ocorre a luta política pelo reconhecimento da EJA na sociedade brasileira (FERREIRA, 2008).

Uma das questões apontadas por Sales e Fischman (2016, p. 13) diz respeito ao fato de que não basta oferecer disciplinas na área da EJA, "Certamente incorporar as palavras 'jovens' e 'adultos' ao título de uma disciplina não é garantia de que esses sujeitos sejam de fato incorporados a ela, pois isso vai depender da formação e/ou da disposição do professor responsável". Portanto, é necessário refletir sobre essa formação, garantindo condições necessárias para que o futuro educador compreenda o que é a $E A^{78}$, tendo em vista as demandas das práticas sociais diárias dos sujeitos, onde

\footnotetext{
78 É importante salientar que as Diretrizes Curriculares Nacionais para a formação inicial em nível superior (cursos de licenciatura, cursos de formação pedagógica para graduados e cursos de segunda licenciatura) e para a formação continuada (Resolução n. 02, de 1 de julho de 2015, do Conselho Nacional de Educação) orientam a formação para as diferentes modalidades, entre elas a Educação de Jovens e Adultos, no parágrafo 5o inciso I (BRASIL, 2015).
} 


\section{RevistAleph}

os conhecimentos estão cada vez mais ilimitados, de forma que atenda à diversidade de necessidades, nas mais diversas condições físicas e sociais referentes à vida.

Os cursos de extensão e o grupo de estudos vêm ao encontro dessas necessidades, pois têm como diretriz principal estudar e analisar os distintos processos que contribuem para a manutenção da baixa escolaridade no Brasil, relacionados à história da EJA, com destaque para as contribuições no campo da educação popular; a incorporação da EJA como direito público a todo cidadão brasileiro e os contraditórios processos pedagógicos que perpassam toda a sua história.

Contudo, conforme analisam Oliveira, Fraga e Vieira (2016, p. 57),

[...] há necessidade de reflexão em torno do lugar restrito conferido às discussões teórico-práticas e político-pedagógicas de temas ligados à Educação de Jovens e Adultos e aos movimentos sociais, articulados na disciplina em foco, conforme o perfil previsto pelas Diretrizes Curriculares Nacionais para o Curso de Pedagogia.

Por isso, as discussões sobre a aprendizagem de jovens, adultos e idosos precisam ser ampliadas e, no Curso de Pedagogia da UERJ, aparecem como extensão da nomenclatura dada às outras disciplinas, como, por exemplo, Educação Matemática para crianças, jovens e adultos. Isso mostra uma preocupação em que não só as disciplinas do campo da EJA trabalhem com a modalidade, mas também todas as outras disciplinas necessitam abordar as concepções e aprendizagens dos sujeitos, em consonância com as Diretrizes Curriculares Nacionais para o Curso de Pedagogia (BRASIL, 2006, Art. 6) que preveem a "aplicação, em práticas educativas, de conhecimentos de processos de desenvolvimento de crianças, adolescentes, jovens e adultos, nas dimensões física, cognitiva, afetiva, estética, cultural, lúdica, artística, ética e biossocial".

Por isso, o projeto de extensão prevê o entendimento do papel da EJA no âmbito do sistema educativo e tensionamentos: relação com outras políticas setoriais e com a diversidade de sujeitos; caráter conservador, reformador ou transformador das políticas públicas que conformam o conjunto de práticas educativas; lutas pelo direito e a garantia de sua identidade com características próprias. Prevê também o estudo sobre o papel da EJA no âmbito do aprender por toda a vida: apropriações contemporâneas e 


\section{RevistAleph}

desafios nas sociedades do conhecimento.

Com o objetivo de fomentar estudos e pesquisas na área da alfabetização de jovens e adultos que contribuam para o reconhecimento e enfrentamento dos principais desafios da área e para a reflexão sobre a prática dos educadores e licenciandos envolvidos, dando suporte à formação inicial e continuada destes sujeitos, assume-se o que Freire (1998, p. 24) afirma quando diz que "a reflexão crítica sobre a prática se torna uma exigência da relação Teoria/Prática sem a qual a teoria pode ir virando blábláblá e a prática, ativismo".

Assim, é importante que os professores e licenciandos possam repensar sua ação, problematizando-a, para que refaçam sua prática pedagógica e, ao mesmo tempo, revejam as teorias que a embasam e a consolidam. Freire (1998) propõe alinhar e discutir saberes que são fundamentais à prática educativo-crítica ou progressista, para que o educador se perceba enquanto sujeito da educação, assim como o educando, e que reconheça que ensinar é criar possibilidades para a produção e a construção de conhecimentos e não transferência de conhecimento, no sentido da concepção bancária da educação.

De acordo com Sales e Fischman (2016), há uma forte tensão entre teoria e prática na formação de educadores. Esta é uma questão que precisa ser enfrentada, visto que as universidades dialogam pouco com a educação básica. A relação se pauta muito mais por críticas de um lado e de outro, do que por uma parceria construtiva. E as disciplinas pedagógicas nem sempre conseguem superar a dicotomia entre teoria e prática, parecendo que são processos estanques, que não se relacionam. Por isso, é necessário pensar em como as universidades podem contribuir para esse debate, de maneira que a partir das disciplinas pedagógicas, no sentido da superação de tal dicotomia.

Sobre esse aspecto, Santos, Freitas e Cavalcante (2016) afirmam o quanto é importante a aproximação entre universidade e escolas. De acordo com a pesquisa das autoras, que trabalham com uma investigação sobre as possíveis relações entre as instituições, não é possível que se aceite que o lugar do estudo teórico pertença à universidade, enquanto às escolas é reservado o lugar da prática. Pois, "toda teoria 


\section{RevistAleph}

advém de uma prática e toda prática é respaldada em uma teoria" (SANTOS, FREITAS e CAVALCANTE, 2016, p. 65). Assim, a escola é também um lugar da formação e não só a universidade. Com essa visão é possível romper a arrogância científica que segrega esses dois campos de atuação, sendo possível um trabalho coletivo e a construção de uma cultura de formação, que se dará em ambos os espaços e em que todos assumam um papel formativo para os sujeitos envolvidos.

Nesse sentido, a própria universidade pode refletir sobre suas práticas formadoras (SANTOS, FREITAS e CAVALCANTE, 2016, p. 66):

Ao exercermos a dupla função de professores universitários e, portanto, formadores, aprendemos que os propósitos e os papéis dessas funções se encontram ou se desencontram. Enquanto pesquisadores buscamos entender o fenômeno investigado, e enquanto formadores contribuir para com o movimento de significação e ressignificação das práticas.

O que se enfatiza aqui é a importância de que as instituições de ensino superior assumam a dimensão da teoria e a dimensão da prática na formação do professor. 0 sentido nessa formação se dará não para os educadores, mas com os educadores. Universidade e escola poderão conviver como parceiras da formação dos educadores, contribuindo para significar e ressignificar as práticas escolares, conforme apontam Santos, Freitas e Cavalcante (2016).

É sobre essa prática educativo-crítica ou progressista que o projeto aqui descrito pretendeu se debruçar. Para tanto, os temas trabalhados têm total relação com a prática pedagógica nas escolas, pois constituem desafios enfrentados no cotidiano, e foram elencados a partir da própria necessidade, trazida pelos educadores em cursos de formação anteriores, de relacionar a formação à realidade das escolas e dos educandos. Assim, a discussão promovida problematiza tais temas e promove uma intervenção na realidade, no sentido da construção de novos conhecimentos e metodologias.

A relação entre ensino, pesquisa e extensão é proporcionada pela aproximação entre a universidade e a escola pública. O papel da universidade na formação de educadores perpassa a pesquisa de alternativas pedagógicas, o resgate e o apoio à sistematização da prática, a divulgação de inovações, a formação continuada e a sua 


\section{RevistAleph}

integração com a comunidade escolar para a elaboração de propostas conjuntas de aperfeiçoamento da educação.

Desde que o projeto se iniciou na própria UERJ, o planejamento de estratégias ocorre entre a coordenadora e a bolsista de extensão, no que se refere à divulgação dos cursos, inscrição de interessados, efetivação de matrículas, convite de professores/formadores para dinamizarem as aulas, condução dos encontros e certificação dos participantes. Todas estas ações ocorrem com aval e apoio do Departamento de Extensão da UERJ.

O projeto dá condição aos licenciandos de entrarem em contato com a realidade das escolas e dos professores da EJA. As trocas pedagógicas e os debates ocorridos garantem que os estudantes já percebam e se envolvam com as questões práticas do cotidiano das escolas.

Pensar sobre a EJA no Brasil significa necessariamente se debruçar sobre uma história de inclusões e exclusões. Hoje, coerentemente após muitos estudos acerca da EJA, é preciso perceber a identidade destas pessoas enquanto sujeitos históricos, que tiveram direitos negados e limitado acesso à educação escolar.

Por isso, torna-se imprescindível a busca pela formação integral dos sujeitos, críticos e reflexivos, capazes de emanciparem-se na realidade dura em que vivem e que quase os obriga a não questionarem o que ocorre, de maneira passiva. Dessa forma, são tão importantes para a formação dos grupos populares certos conteúdos que o educador lhes deve ensinar, quanto a análise que eles façam de sua realidade concreta, buscando um saber mais crítico e menos ingênuo (FREIRE, 1998).

A psicologia do desenvolvimento humano já não sustenta a ideia de que exista uma idade apropriada para aprender. Pesquisas demonstram que a aprendizagem ocorre em qualquer idade, ainda que a pertinência a determinados grupos socioculturais ou etários possa estar relacionada à variância nas funções, características e estilos cognitivos (OLIVEIRA, 1999; 2004). Portanto, é necessário que o educador, ainda na formação inicial, tome consciência da situação atual da EJA. E que, no momento da licenciatura, o profissional da EJA receba formação em teorias pedagógicas sobre a adolescência, a juventude, a vida adulta e o envelhecimento, a fim de conhecer e 


\section{RevistAleph}

perceber o seu aluno como sujeito de direitos, respeitando seus saberes e sua realidade (BRASIL, 2000).

\section{Sobre as aprendizagens realizadas}

A avaliação do processo de aprendizagem dos participantes do projeto se dá por meio da participação nos encontros (assiduidade, atuação nos debates e realização das tarefas propostas). Ao longo dos encontros são produzidos textos, relatos, diálogos e relatórios pelos envolvidos, no sentido de avaliar tanto a condução do curso quanto sua aprendizagem. Esta metodologia vai ao encontro de uma avaliação formativa, pois ela pretende enfrentar o desafio da formação integral dos sujeitos, na intenção de, partindo dos conhecimentos que os licenciados já dominam, favorecer a construção de novos conhecimentos. Esta avaliação do processo tem um cunho qualitativo, que considera os sujeitos envolvidos, suas histórias de vida, seus saberes e experiências.

Os textos produzidos, em atividades presenciais e/ou não presenciais, são socializados nos encontros. A troca das experiências produzidas favorece que os participantes se conheçam melhor e aprendam uns com os outros. Neste espaço de troca, os participantes podem se colocar, falar de si e da relação que estabelecem com o conhecimento, expondo suas motivações, seus desejos, suas crenças e suas histórias de vida.

Além disso, são certificados apenas aqueles participantes que estiverem presentes em pelo menos $75 \%$ do total de encontros. Não só a presença é avaliada, mas também a participação ativa deles nos encontros, com fala, debate, proposição de ideias e reflexões. Diante desta prática, a avaliação serve como uma constante observação dos participantes, do que sabem, do que não sabem, de como dialogam como os saberes construídos, de como elaboram seu pensamento e de como articulam as informações recebidas, entre outras questões.

Ao final dos cursos de extensão, sempre é solicitada ao grupo uma avaliação do curso, em que os participantes sintetizam suas principais impressões a respeito da formação (aprendizagens, dificuldades, expectativas alcançadas ou não etc.). Dentre os 


\section{RevistAleph}

pontos abordados pelos cursistas estão: a relevância das atividades práticas; a partilha de aprendizados, troca de ideias e a reflexão coletiva; o despertar do interesse para os estudos e a pesquisa de novas metodologias de trabalho; a participação de professores de diferentes escolas, favorecendo a troca de experiências; o empenho dos formadores, o domínio dos temas abordados e o estímulo aos licenciandos; a relação entre teoria e prática presente em todos os encontros do curso; a contribuição para a formação inicial e continuada dos educadores, entre outros aspectos.

Essas e outras impressões foram levadas em consideração no intuito de garantir essas experiências e proporcionar outras aos professores e licenciandos envolvidos. Para tanto, os encontros, como espaço de troca, fomentaram a construção de novas experiências, conhecimentos e diálogos.

Os participantes também são convidados a se autoavaliarem ao final dos cursos de extensão. A autoavaliação permite ao participante escolher seus acontecimentos mais significativos, selecionar as atividades mais importantes que realizou. Este momento garante que eles realizem uma reflexão sobre a sua participação no curso e apontem pontos em que poderiam ter se esforçado mais.

Nesse sentido, a formação assume-se como um repensar de práticas e geração de novas leituras do mundo e da realidade, e não como um espaço burocrático, normativo e regulador da ação pedagógica. Os cursos de extensão trazem à tona as dificuldades enfrentadas pelos educadores e licenciandos na alfabetização de jovens e adultos, mas também seus sucessos e práticas bem-sucedidas.

Aprender, neste sentido, é muito mais do que assimilar conteúdos curriculares, realizar atividades e certificar-se. Significa reafirmar o compromisso a formação integral e humana dos sujeitos, em processo de mudança e contato com novas maneiras de ver, pensar, fazer ou falar, objetivando a construção de conhecimento, a troca de experiências e a formação para a docência. A aprendizagem, assim, é baseada em um processo de emancipação social, que requer conscientização e problematização da realidade.

\section{Considerações finais}




\section{RevistAleph}

Como uma das contribuições do projeto de extensão "Desafios e possibilidades atuais na Alfabetização de Jovens e Adultos" destaca-se a crescente troca de conhecimentos em todos os encontros promovidos. Estes são espaços de ensino e de aprendizagem para todos os participantes. Como seres inconclusos (FREIRE, 1998), não estamos completos, acabados, continuamos em permanente processo de formação, e estar com o grupo, ouvir suas experiências, dialogar com os participantes, são ações que fazem parte deste processo. As aprendizagens são inúmeras e contribuem para um certo amadurecimento a cada atividade que se executa no âmbito deste projeto.

É fundamental salientar o reconhecimento de que não é possível assumir a responsabilidade pela condução do projeto isoladamente. A coordenação do projeto necessita de braços que ajudem na realização das atividades. As ideias são muitas, mas sem auxílio, algumas ficam impossibilitadas de acontecerem.

À medida que o projeto avançou, com seus cursos e com os estudos do grupo, percebeu-se o quanto a capacidade de reflexão sobre a prática docente pode ser aprimorada. O trabalho buscou continuamente esta transformação, apontando que o olhar da coordenação e dos participantes é capaz de mudar, reconhecendo erros e refazendo caminhos.

A avaliação formativa e processual, proposta nos cursos, sem a obrigatoriedade de provas, testes ou conceitos corresponde a uma prática que pode ser introduzida na sala de aula da EJA, quando os licenciandos forem professores. Esta forma de avaliação pode ser um instrumento de reflexão sobre a prática avaliativa de educadores, não só na EJA, mas em outras modalidade e níveis de ensino.

O que contagia neste trabalho é o entusiasmo dos envolvidos. A participação dos professores e licenciandos é animadora. São assíduos e perseverantes nos encontros. Além disso, solicitam estudos e aprofundamentos, para além das aulas, mostrando-se bastante comprometidos com as atividades do projeto.

É importante reconhecer a necessidade de cursos de formação de alfabetizadores para a EJA. Esta área ainda carece de estudos e pesquisas para que seja reconhecida como direito de todos os não escolarizados e se desvencilhe do estigma 


\section{RevistAleph}

assistencialista que ainda existe. Muitos participantes se inscrevem no curso acreditando que a alfabetização na EJA é obra de caridade, boa vontade. E ao longo do curso, vão percebendo e aprendendo a importância da formação de educadores para este campo.

Nestes quatro anos de implementação do projeto foram oferecidos cinco cursos de extensão, que certificaram, no total, 169 pessoas. Deste total, mais de $60 \%$ foi composto por licenciandos, tanto da UERJ quanto de outras Instituições de Ensino Superior. Além dos participantes dos cursos, há também os participantes do Grupo de Estudos, que vêm se reunindo permanentemente desde 2019. Este grupo conta com cerca de 15 licenciandos, que se encontram quinzenalmente e se constitui em um espaço de discussão, troca de experiências e estudos sobre a área.

Por último, saliento que a formação precoce e continuada de alfabetizadores da EJA, encontra-se em consonância com a atual demanda, pois possibilita o repensar de práticas pedagógicas que dialogam com a realidade vivenciada nas escolas e nas salas de aula, conduzido por um olhar crítico e criativo sobre os educandos e o processo de ensino e de aprendizagem. Ainda que sejam inúmeros os desafios impostos pela realidade, eles necessitam ser problematizados e tensionados pelos educadores envolvidos na modalidade. Um projeto dessa natureza mostra-se como um espaço essencial para essa reflexão. 


\section{RevistAleph}

\section{Referências}

ARROYO, Miguel G. Formar educadoras e educadores de jovens e adultos. In: SOARES, Leôncio. (Org.). Formação de Educadores de Jovens e Adultos. Belo Horizonte: Autêntica/SecadMec/Unesco, 2006.

BRASIL. Ministério da Educação. Conselho Nacional de Educação. Resolução CNE/CP no 1, de 15 de maio de 2006. Institui Diretrizes Curriculares Nacionais para o Curso de Graduação em Pedagogia, licenciatura. Brasília: CNE: MEC, 2006.

BRASIL. Ministério da Educação. Conselho Nacional de Educação. Parecer CNE/CEB n. 11/2000. Estabelece as Diretrizes Curriculares Nacionais para a Educação de Jovens e Adultos. Brasília: CNE: MEC, 2000.

BRASIL. Ministério da Educação. Conselho Nacional de Educação. Resolução n. 2, de 10 de julho de 2015. Define as Diretrizes Curriculares Nacionais para a formação inicial em nível superior (cursos de licenciatura, cursos de formação pedagógica para graduados e cursos de segunda licenciatura) e para a formação continuada. Brasília: CNE: MEC, 2015.

DI PIERRO, Maria Clara; VÓVIO, Cláudia Lemos; ANDRADE, Eliane Ribeiro. Alfabetização de jovens e adultos no Brasil: lições da prática. Brasília: UNESCO, 2008. Disponível em: http://bibliotecadigital.puc-campinas.edu.br/services/e-books/162640por.pdf Acesso em 17 abr 2020.

FERREIRA, Luiz Olavo Fonseca. Que diretrizes devem nortear a formação inicial e continuada dos educadores de jovens e adultos? Perspectiva dos professores de jovens e adultos da educação básica. In: MACHADO, M. M. (Org.). Formação de educadores de jovens e adultos. Brasília: Secad/MEC, Unesco, 2008.

FREIRE, Paulo. Pedagogia da autonomia: saberes necessários à prática educativa. 7ạ ed. São Paulo: Paz e Terra, 1998.

IBGE. Pesquisa Nacional por Amostra de Domicílios Contínua (PNAD Contínua) 2017. Disponível em: http://www.ibge.gov.br Acesso em 02 mai 2020.

OLIVEIRA, Edna Castro de; FRAGA, Elizangela Ribeiro; VIEIRA, Tatiana de Santana. EJA, movimentos sociais e formação inicial de educadores na universidade. Revista Teias, v. 17. Edição Especial - Práticas nas IES de formação de professores para a EJA. Rio de Janeiro: UERJ, 2016. Disponível em: https://www.epublicacoes.uerj.br/index.php/revistateias/article/view/25012 Acesso em 01 mai 2020.

OLIVEIRA, Marta Kohl de. Jovens e adultos como sujeitos de conhecimento e aprendizagem. Revista Brasileira de Educação. Set/Out/Nov/Dez. 1999. Disponível em: http://eixovpsicologia.pbworks.com/f/texto+6.pdf Acesso em 17 set 2020.

OLIVEIRA, Marta Kohl. Ciclos de vida: algumas questões sobre a psicologia do adulto. Educação e Pesquisa. São Paulo, v. 30, n. 02, maio/ago. 2004. Disponível em:

https://www.scielo.br/pdf/ep/v30n2/v30n2a02.pdf Acesso em 18 set 2020. 


\section{RevistAleph}

PAIVA, Jane. FERNANDES, Fátima Lobato. Da concepção à prática de formação inicial: a EJA no currículo de pedagogia. Revista Teias, v. 17. Edição Especial - Práticas nas IES de formação de professores para a EJA. Rio de Janeiro: UERJ, 2016. Disponível em: https://www.e-

publicacoes.uerj.br/index.php/revistateias/article/view/25007 Acesso em 18 abr 2020.

SALES, Sandra Regina; FISCHMAN, Gustavo E. Propostas para ir além da "persistência da burrice" e outras "ideias zumbi" na EJA. Revista Teias, v. 17. Edição Especial - Práticas nas IES de formação de professores para a EJA. Rio de Janeiro: UERJ, 2016. Disponível em:

https://www.e-publicacoes.ueri.br/index.php/revistateias/article/view/25004 Acesso em 19 abr 2020.

SANTOS, Adriana Cavalcanti dos; FREITAS, Marinaide Lima Q.; CAVALCANTE, Valéria Campos. Formação inicial e continuada do professor da EJA: práticas e saberes gerados entre universidade-escola. Revista Teias, v. 17. Edição Especial - Práticas nas IES de formação de professores para a EJA. Rio de Janeiro: UERJ, 2016. Disponível em: https://www.epublicacoes.ueri.br/index.php/revistateias/article/view/25034 Acesso em 30 abr 2020.

ZANETTI, Maria Aparecida. Reflexões sobre a formação de educadores de jovens e adultos em redes de ensino públicas. In: MACHADO, M. M. (Org.). Formação de educadores de jovens e adultos. Brasília: Secad/MEC, Unesco, 2008.

Data de envio: $23 / 05 / 2020$

Data de aceite: $27 / 11 / 2020$. 